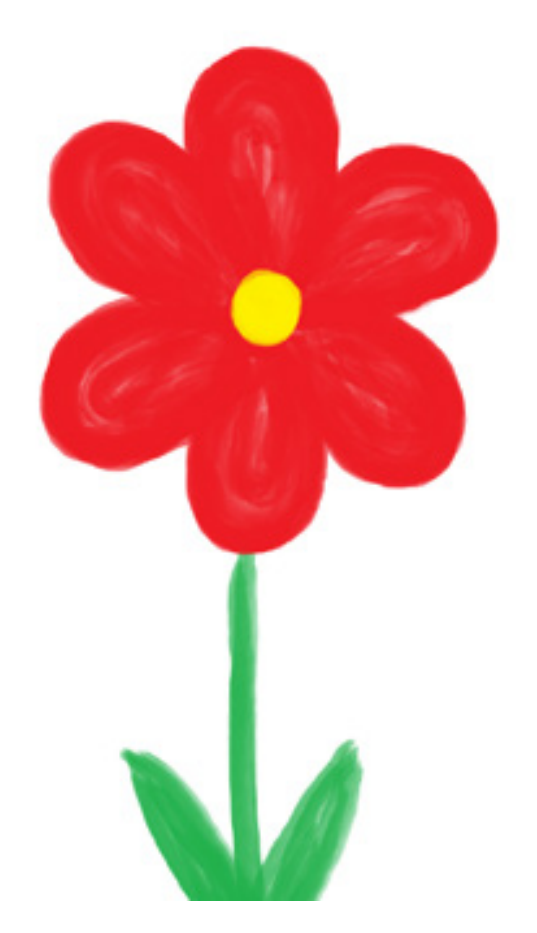

\section{Una flor roja con el tallo verde}

MIGUEL ANGEL SANTOS GUERRA
BLOG EL ADARVE (ENTRADA 13/09/2008)
Comienza un nuevo curso escolar. Abren de nuevo sus puertas los colegios e Institutos, que son talleres de aprendizaje laboratorios de que son talleres de aprendizaje laboratorios de
ciudadanía. El profesorado se incorpora a sus puestos de trabajo, agrupado en equipos que multiplican la eficacia de la acción educativa. Los alumnos y alumnas acuden con sus mochilas llenas de libros, de nostalgia y de nerviosismo. Los papás, que en los veranos descubren de nuevo la import quán nuevo la importancia y la dificultad de estar ininterrumpidamente con los hijos, los llevan los colegios preocupados por la suerte que van a correr.

- ¿Quién va a ser su tutor este curso?, preguntan inquietos.

La respuesta (si ya conocen al profesorado) los llenará de satisfacción o de graves preocupaciones. Qué buena noticia es para un profesional de la educación que los padres y madres, cuando conocen que su hijo va a estar en sus manos, se llenen de alegría.

Todos a pensar. Todos a trabajar. Todos a convivir. Cada uno en la parte que le corresponde para que ese proyecto compartido tenga éxito. Si una de las partes no cumple con su función, el fracaso está asegurado. Por eso brindo a cada uno de los integrantes de la comunidad este sencillo eslogan: por mí que no quede.

¿Qué es lo que se pretende? ¿Qué es lo que se hace? ¿Qué es lo que se consigue? No basta con repetir las rutinas. No es suficiente diseñary desarrollar un currículum en el que se explicitan los objetivos y los métodos. No basta la buena voluntad. Hay que preguntarse por los efectos subrepticios que lleva co subrepticios que lleva consigo una manera determinada de actuar.

Hace unos años llegó a mis manos un sencillo e interesante relato de una profesora argentina llamada Helen E. Buckley. En su extrema simplicidad encierra una carga abrumadora de interrogantes. El texto no necesita comentario interrogantes. El texto no necesita comentario
alguno. Su pretensión didáctica es tan contundente que nos aboca inexorablemente a la reflexión y al debate. Dice así:
Una vez un niño fue a la escuela. El niño era muy pequeño y la escuela muy grande. Cuando el niño descubrió que podía ir a su aula con sólo andar en línea recta, se sintió feliz. Y ya no siguió pareciéndole que la escuela fuera tan grande. Una mañana, cuando el niño ya llevaba un rato en la escuela, la maestra dijo:

- Hoy vamos a hacer un dibujo.

- Muy bien, pensó el niño. Porque a él le gustaba dibujar. Podía pintar leones y tigres, gallinas y vacas, trenes y barcos... Y sacó sus lápices de colores y se puso a dibujar. Pero la maestra dijo: - Esperad. Aún no es el momento de empezar. Y esperó a que todos estuvieran dispuestos.

- Ahora, dijo la maestra. Vamos a dibujar flores. - Qué bien, pensó el niño, porque a él le gustaba pintar flores. Y empezó a dibujar bonitas flores, con sus lápices rosados, amarillos, azules y verdes. Pero la maestra dijo:

- Esperad, que yo os mostraré cómo se hacen. - Así, dijo la maestra.

Y dibujó sobre la pizarra una flor roja con el tallo verde.

- Ya, dijo la maestra. Ahora ya podéis empezar.

El niño miró la flor de la maestra y después miró la suya. A él le gustaba más su flor que la de la maestra, pero no lo dijo. Y se limitó a dar la vuelta a la hora para hacer una flor como la de la maestra: era roja con tallo verde.

Otro día, cuando el niño había abierto él solo la puerta de entrada, la maestra dijo:

- Hoy vamos a trabajar con plastilina.

- Bien, pensó el niño. Porque a él le encantaba la plastilina. Podía hacer con ella toda clase de objetos: serpientes y muñecos, elefantes y ratones, coches y trenes... Y empezó a amasar un puñado de plastilina. Pero la maestra dijo: - Esperad, no es hora de comenzar.

Y él esperó hasta que todos estuvieron dispuestos.

- Ahora, dijo la maestra. Vamos a hacer una víbora.
- Qué bien, pensó el niño. Porque a él le gustaba hacer víboras. Y empezó a hacerlas de distintos colores y tamaños. Pero la maestra dijo:

- Esperad a que yo os enseñe.

Y entonces les enseñó a hacer una viborita larga.

- Ahora, les dijo, ya podéis empezar.

El niño miró la viborita que había hecho la maestra y después la suya. Las suya le gustaba más que la de la maestra, pero no reveló nada de eso. Y se limitó a amasar la bola de plastilina y a hacer una viborita como la de la maestra.

Así, poco a poco el niño aprendió a esperar y a observar y a hacer las cosas igual que la maestra. Y muy pronto dejó de hacer las cosas por sí mismo.

Entonces sucedió que el niño y su familia se mudaron a otra casa en otra ciudad y el niño tuvo que ir a otra escuela. Una escuela aún más grande que la anterior. Tenía que subir unos grandes escalones y caminar por un pasillo largo para llegar a su aula. Y el primer día de clase, la maestra, dijo:

- Hoy vamos a hacer un dibujo.

- Bien, pensó el niño. Y se quedó esperando a que ella le dijera lo que tenía que hacer. Pero la maestra no dijo nada. Se paseaba entre los niños y las niñas por el aula. Cuando llegó junto al niño

le preguntó si no quería dibujar.
- Sí, dijo él. Pero, ¿qué vamos a hacer?

- Yo no sé hasta que tú lo hagas, dijo la maestra. - Pero, ¿cómo tengo que hacerlo? - Como a ti te guste, dijo la maestra.

- ¿Y de qué color?, preguntó el niño.

- Del que tú quieras. Si todos hiciéseis el mismo dibujo y usaseis los mismos colores, ¿cómo iba a saber yo cuál era de cada uno?

- Yo no sé, dijo el niño. Y comenzó a hacer una flor roja con el tallo verde.

Pues bien, yo quisiera que en todas las escuelas estallase con el nuevo curso una primavera incontenible de flores variadas, irrepetibles y multicolores 